\title{
Vasorelaxant and Hypotensive Effects of Cheonwangbosimdan in SD and SHR Rats
}

\author{
Bumjung Kim $\mathbb{D}$, ${ }^{1}$ Cheolmin Jo $\mathbb{D},{ }^{2}$ Ho-Young Choi $\mathbb{D},{ }^{1}$ and Kyungjin Lee $\mathbb{D}^{1}$ \\ ${ }^{1}$ Department of Herbology, College of Korean Medicine, Kyung Hee University, Seoul 02447, Republic of Korea \\ ${ }^{2}$ Department of Herbology, Graduate School, Kyung Hee University, Seoul 02447, Republic of Korea
}

Correspondence should be addressed to Kyungjin Lee; niceday@khu.ac.kr

Received 2 March 2018; Accepted 26 June 2018; Published 10 July 2018

Academic Editor: José L. Rios

Copyright (C) 2018 Bumjung Kim et al. This is an open access article distributed under the Creative Commons Attribution License, which permits unrestricted use, distribution, and reproduction in any medium, provided the original work is properly cited.

\begin{abstract}
Historically, traditional herbal medicines (THMs) have been the conventional treatment strategy in the Korean medical system for treating many diseases. However, THMs have rarely been used to treat hypertension, and moreover few studies have investigated the interaction of blood pressure with the coadministration of synthetic antihypertensives. We aimed to evaluate the vasorelaxant and hypotensive effects of the traditional herbal prescription Cheonwangbosimdan (CWBSD; "Tianwangbuxindan" in Chinese) and the combination of CWBSD with amlodipine. CWBSD was extracted with distilled water at $100^{\circ} \mathrm{C}$ for $2 \mathrm{~h}$. To investigate vasorelaxant activities, CWBSD with amlodipine $(10 \mu \mathrm{g} / \mathrm{ml})$ was added cumulatively $(10-1,000 \mu \mathrm{g} / \mathrm{ml})$ to isolated rat aortic rings precontracted using phenylephrine or potassium chloride in organ chambers. To investigate hypotensive effects, CWBSD $(2,476 \mathrm{mg} / \mathrm{kg}) \mathrm{was}$ orally administered with or without amlodipine $(5 \mathrm{mg} / \mathrm{kg}$ ) to spontaneously hypertensive rats (SHRs). CWBSD increased the relaxation of rat aortic rings induced by amlodipine $(P<0.01)$. In vivo, CWBSD coadministration with amlodipine also significantly decreased the blood pressure of SHRs compared to the amlodipine-treated group. These results suggested that CWBSD could be a useful herbal prescription to treat hypertension and we recommend establishing guidelines for the use of herbal medicines in conjunction with antihypertensive drugs, including amlodipine.
\end{abstract}

\section{Introduction}

Hypertension is a major risk factor for cardiovascular disease, chronic kidney disease, cerebrovascular disease, ischemic heart disease, stroke, and coronary heart disease. Approximately $30 \%$ of adults in the United States are not aware of their hypertension and in two-thirds of patients, hypertension is not being controlled [1]. According to the Korean National Health and Nutrition Examination Survey, the prevalence of hypertension among adults aged over 30 years was approximately $30 \%$ in Korea. The prevalence of hypertension has not been constant over time; the prevalence was $29 \%$ in 1998 , decreased slightly to $24 \%$ in 2007 , and then increased again to $28 \%$ in 2011 [2]. Despite the improvement in the treatment rate of hypertension, some older patients still have untreated and uncontrolled hypertension. Although the prevalence of hypertension has remained relatively stable over the last several decades, the number of older people with hypertension has been steadily increasing due to a rapidly aging society. In particular, isolated systolic hypertension, one of four subtypes of hypertension, is becoming more prevalent [3].

Historically, traditional herbal medicines (THMs) have been the conventional treatment method in the Korean medical system for treating various diseases. Traditional Korean medicine, which was discovered around 5,000 years ago, has peculiar medical theories and strategies to treat diseases [4]. In Korea, despite the long history of using THMs for the treatment of many diseases, they are rarely used in patients with hypertension due to a lack of evidencebased data. Moreover, few studies have been conducted on the interaction of synthetic antihypertensive drugs and THMs, even though hypertensive patients have been taking antihypertensive drugs such as amlodipine with traditional herbal prescriptions in Korea.

Over three-fourths of the world's population uses THMs, because they may be beneficial and have few side effects. However, some adverse effects and potential toxicities of THMs have been reported. Therefore, further study will be necessary to estimate their efficacy, quality, and safety 
[5]. Additionally, few studies have been conducted on the effect of coadministration of THMs and Western drugs such antihypertensive drugs on blood pressure.

THMs, composed of various components, may be beneficial to treat hypertension. Although patients with hypertension use THMs to improve their health, Western medical practitioners prohibit or discourage taking herbal medicine with antihypertensive drugs. Therefore, it is necessary to investigate the hypotensive activities of THMs and interactions of coadministration of amlodipine and herbal prescriptions. In our previous study, we investigated the vasorelaxant effects of 50 commonly used traditional herbal prescriptions on isolated rat aortic rings. Among them, Cheonwangbosimdan (CWBSD; "Tianwangbuxindan" in Chinese) showed the most remarkable vasorelaxant effects.

CWBSD is often used in Korea to treat depressive and anxiety disorders, including posttraumatic stress disorder and obsessive-compulsive disorder. This prescription is composed of 15 herbal medicines including Rehmanniae Radix, Coptidis Rhizoma, Acori Graminei Rhizoma, Ginseng Radix, Angelicae Gigantis Radix, Schisandrae Fructus, Asparagi Tuber, Liriopis seu Ophiopogonis Tuber, Thujae Semen, Zizyphi Semen, Scrophulariae Radix, Poria Sclerotium, Salviae Miltiorrhizae Radix, Platycodonis Radix, and Polygalae Radix. A previous study analyzed 7 bioactive compounds, including 5-hydroxymethyl-2-furaldehyde (5HMF) from Asparagus cochinchinensis, berberine and coptisine from Coptis japonica, nodakenin from Angelica gigas, harpagoside and cinnamic acid from Scrophularia buergeriana, and $\beta$-asarone from Acorus gramineus, for quality control of CWBSD by HPLC-PDA [6]. In recent studies, CWBSD has been shown to have antioxidant [7], antidepressant [8], and neuroprotective effect [9], effects against Alzheimer's disease [10-12], effects that increase gamma-aminobutyric acid [13], and effects on the central nervous system and cardiovascular system [14].

To provide evidence and guidelines for the use of CWBSD or a combination of CWBSD and amlodipine in patients with hypertension, we investigated the vasorelaxant and hypotensive effects of CWBSD and the combination of CWBSD and amlodipine using isolated rat aortic rings and spontaneously hypertensive rats (SHRs).

\section{Materials and Methods}

2.1. Material and Extraction. The water extract of CWBSD was provided by the Korea Institute of Oriental Medicine in Korea. It is a complex powder extracted from 15 kinds of herbal medicines (Table 1). Extraction protocol was as follows: CWBSD was extracted once in distilled water at $100^{\circ} \mathrm{C}$ for $2 \mathrm{~h}$ using an electric extractor (COSMOS660; Kyungseo Machine Co., Incheon, Korea). The extract was evaporated and freeze-dried to obtain a powder after filtration. The yield of CWBSD extract was $21.3 \%$. The CWBSD powder was accurately weighed $(0.1 \mathrm{~g})$, suspended in $1 \mathrm{ml}$ of distilled water, and placed into an ultrasonic device for $1 \mathrm{~min}$ for solubilization. The powder was completely dissolved in Krebs-Henseleit $(\mathrm{KH})$ buffer and distilled water.
2.2. Animals. Sprague-Dawley rats (male, 240-260 g, 8 weeks old) and spontaneously hypertensive rats (SHR/lzm; male, 200-250 g; 8 weeks old) were purchased from Raonbio (Gyeonggi province, Korea) and housed under standard laboratory conditions $\left(22 \pm 2^{\circ} \mathrm{C}\right.$; lighting, 07:00-19:00) and were given food and water ad libitum. All procedures followed the animal welfare guidelines and were approved [KHUASP (SE)16-143] by the Kyung Hee University Institutional Animal Care and Use Committee.

2.3. Preparation of Rat Aortic Rings. The rat thoracic aorta was isolated and stored in $\mathrm{KH}$ buffer $(\mathrm{mM}), \mathrm{NaCl} 118.0, \mathrm{KCl}$ 4.7, $\mathrm{MgSO}_{4} 1.2, \mathrm{KH}_{2} \mathrm{PO}_{4} 1.2, \mathrm{CaCl}_{2} 2.5, \mathrm{NaHCO}_{3} 25.0$, and glucose 11.1, and then oxygenated with a gas mixture of $95 \%$ $\mathrm{O}_{2}-5 \% \mathrm{CO}_{2}$. After careful removal of the connective tissue and surrounding fat, the aorta was cross-sectioned into $2 \mathrm{~mm}$ rings and placed in organ chambers containing $10 \mathrm{ml} \mathrm{KH}$ buffer at $37^{\circ} \mathrm{C}$ and $\mathrm{pH} 7.4$. The rings were suspended between two tungsten stirrups for the measurement of isometric tension by a force transducer (Grass Instrument Co., USA). After equilibration under no tension for $30 \mathrm{~min}$, the aortic rings were incubated for $1 \mathrm{~h}$ at a resting tension of $1.2 \mathrm{~g}$. During the equilibration period, the $\mathrm{KH}$ buffer was changed every 15-20 min for $90 \mathrm{~min}$. Isometric transducers connected to a data acquisition system (PowerLab, ADI instrument Co., Australia) were used to measure the changes in tension of the aortic rings.

\subsection{Experimental Protocols}

2.4.1. Effects of CWBSD on Phenylephrine- (PE-) or Potassium Chloride- (KCl-) Induced Contraction. Studies were performed on rat aortic rings precontracted with $\mathrm{PE}(1 \mu \mathrm{M})$ or $\mathrm{KCl}(60 \mathrm{mM})$ in $\mathrm{KH}$ buffer. Following equilibration period, the effect of various cumulative doses of CWBSD (10-1,000 $\mu \mathrm{g} / \mathrm{ml}$ ) was measured. The vasorelaxant effect of CWBSD was expressed as a percentage relaxation of the response to PE- or $\mathrm{KCl}$-induced contraction.

2.4.2. Effects of CWBSD on Extracellular $\mathrm{Ca}^{2+}$-Induced Contraction via Receptor-Operative $\mathrm{Ca}^{2+}$ Channels (ROCCs) or Voltage-Dependent $\mathrm{Ca}^{2+}$ Channels (VDCCs). The vasorelaxant effect of CWBSD $(600 \mu \mathrm{g} / \mathrm{ml})$ was tested on ROCCs or VDCCs by $\mathrm{PE}(1 \mu \mathrm{M})$ or $\mathrm{KCl}(60 \mathrm{mM})$ pretreatment. ROCCs are activated by PE and VDCCs are activated by $\mathrm{KCl}$. After CWBSD preincubation for $10 \mathrm{~min}$, endotheliumdenuded aortic rings were treated with $\mathrm{PE}$ or $\mathrm{KCl}$, and then the contractile response induced by $\mathrm{CaCl}_{2}(0.3-10 \mathrm{mM})$ was tested. The contraction responses induced by extracellular $\mathrm{Ca}^{2+}$ with or without (control) CWBSD preincubation were compared.

2.4.3. Effects of CWBSD after Treatment of Amlodipine on $P E-I n d u c e d$ Contraction. We investigated the concentrationdependent vasorelaxant activities of CWBSD (10-1,000 $\mu \mathrm{g} / \mathrm{ml}$ ) after relaxing aortic rings with amlodipine (10 $\mu \mathrm{g} / \mathrm{ml})$. The vasorelaxant effect of CWBSD was expressed as a percentage relaxation of the response to $\mathrm{PE}$-induced contraction. 
TABLE 1: The components of Cheonwangbosimdan.

\begin{tabular}{|c|c|c|c|c|}
\hline Herbal name & Scientific name & Part & Collection region & Amount (g) \\
\hline Rehmanniae Radix & $\begin{array}{c}\text { Rehmannia glutinosa (Gaertn.) } \\
\text { DC. (Plantaginaceae) }\end{array}$ & Root & Andong, Korea & 15.0 \\
\hline Coptidis Rhizoma & $\begin{array}{c}\text { Coptis japonica (Thunb.) Makino } \\
\text { (Ranunculaceae) }\end{array}$ & Rhizome & China & 7.5 \\
\hline Acori Graminei Rhizoma & $\begin{array}{c}\text { Acorus gramineus Aiton } \\
\text { (Acoraceae) }\end{array}$ & Rhizome & Jeju, Korea & 3.75 \\
\hline Ginseng Radix & $\begin{array}{l}\text { Panax ginseng C.A. Mey. } \\
\text { (Araliaceae) }\end{array}$ & Root & Yeongju, Korea & 1.875 \\
\hline Angelicae Gigantis Radix & Angelica gigas Nakai (Apiaceae) & Root & Bonghwa, Korea & 1.875 \\
\hline Schisandrae Fructus & $\begin{array}{c}\text { Schisandra chinensis (Turcz.) } \\
\text { Baill. (Schisandraceae) }\end{array}$ & Fruit & Samcheok, Korea & 1.875 \\
\hline Asparagi Tuber & $\begin{array}{c}\text { Asparagus cochinchinensis (Lour.) } \\
\text { Merr. (Asparagaceae) }\end{array}$ & Root & China & 1.875 \\
\hline $\begin{array}{l}\text { Liriopis seu Ophiopogonis } \\
\text { Tuber }\end{array}$ & $\begin{array}{l}\text { Liriope muscari (Decne.) L.H. } \\
\text { Bailey (syn: Liriope platyphylla } \\
\text { F.T. Wang \& Tang, Asparagaceae) }\end{array}$ & Root & Miryang, Korea & 1.875 \\
\hline Thujae Semen & $\begin{array}{c}\text { Platycladus orientalis (L.) Franco } \\
\text { (syn: Thuja orientalis L., } \\
\text { Cupressaceae) }\end{array}$ & Seed & China & 1.875 \\
\hline Zizyphi Semen & $\begin{array}{l}\text { Ziziphus jujuba Mill. } \\
\text { (Rhamnaceae) }\end{array}$ & Seed & China & 1.875 \\
\hline Scrophulariae Radix & $\begin{array}{c}\text { Scrophularia buergeriana Miq. } \\
\text { (Scrophulariaceae) }\end{array}$ & Root & Uiseong, Korea & 1.875 \\
\hline Poria Sclerotium & $\begin{array}{l}\text { Wolfiporia extensa (Peck.) Ginns } \\
\text { (Syn: Poria cocos (Schwein.) F.A. } \\
\text { Wolf, Polyporaceae) }\end{array}$ & Sclerotium & $\begin{array}{l}\text { Pyeongchang, } \\
\text { Korea }\end{array}$ & 1.875 \\
\hline Salviae Miltiorrhizae Radix & $\begin{array}{c}\text { Salvia miltiorrhiza Bunge } \\
\text { (Lamiaceae) }\end{array}$ & Root & China & 1.875 \\
\hline Platycodonis Radix & $\begin{array}{l}\text { Platycodon grandiflorus (Jacq.) } \\
\text { A.DC (Campanulaceae) }\end{array}$ & Root & Muju, Korea & 1.875 \\
\hline Polygalae Radix & $\begin{array}{c}\text { Polygala tenuifolia Willd. } \\
\text { (Polygalaceae) }\end{array}$ & Root & China & 1.875 \\
\hline Total amount & & & & 48.75 \\
\hline
\end{tabular}

2.5. Measurement of Blood Pressure. The systolic blood pressure (SBP) of SHRs was measured using the noninvasive tail cuff system (CODA 8-Channel High Throughput Noninvasive Blood Pressure system, Kent Scientific Co. Ltd., Torrington, CT, USA). They were randomly divided into five groups of five animals each. CWBSD and amlodipine were dissolved in distilled water for this experiment. Each rat was orally given CWBSD $(247.6 \mathrm{mg} / \mathrm{kg})$, CWBSD $(1,238$ $\mathrm{mg} / \mathrm{kg})$, CWBSD (2,476 mg/kg), amlodipine (5 mg/kg), or coadministered amlodipine $(5 \mathrm{mg} / \mathrm{kg})$ and CWBSD $(2,476$ $\mathrm{mg} / \mathrm{kg}$ ). The blood pressure of SHRs was measured at 0 (control), $0.5,1,2$, and $4 \mathrm{~h}$ after drug administration.

2.6. Statistical Analysis. Data are expressed as mean \pm standard error of mean (SEM) and analyzed using IBM SPSS version 23.0 statistical analysis software (SPSS Inc., Chicago, IL, USA). Comparisons of analytical results were performed using Student's t-test or one-way analysis of variance (ANOVA) followed by Tukey's post hoc test. Data with $\mathrm{p}$ values less than 0.05 were considered statistically significant.

\section{Results}

3.1. Vasorelaxant Effects of CWBSD on PE- or KCl-Induced Contraction. CWBSD treatment led to a concentrationdependent vasorelaxant activity in endothelium-intact aortic rings precontracted with $\mathrm{PE}(1 \mu \mathrm{M})$ or $\mathrm{KCl}(60 \mathrm{mM})$. The maximal relaxant effect was $91.5 \pm 6.9 \%$ and $27.2 \pm 5.4 \%$ at the concentration of $1,000 \mu \mathrm{g} / \mathrm{ml}$, respectively (Figure 1).

\subsection{Vasorelaxant Effect of CWBSD on Extracellular ROCCs or} VDCCs. $\mathrm{Ca}^{2+}$-induced contraction was obtained by cumulative addition of $\mathrm{CaCl}_{2}(0.3-10 \mathrm{mM})$. Pretreatment with CWBSD $(600 \mu \mathrm{g} / \mathrm{ml})$ significantly inhibited the contraction induced by extracellular $\mathrm{CaCl}_{2}(10 \mathrm{mM})$ in $\mathrm{Ca}^{2+}$-free $\mathrm{KH}$ buffer and the contraction decreased to $0.97 \pm 0.05$ and 0.29 \pm 0.06 compared to control group $(1.74 \pm 0.08$ and $1.27 \pm$ 0.07 ) in aortic rings pretreated with $\mathrm{PE}$ and $\mathrm{KCl}$, respectively (Figure 2).

3.3. Vasorelaxant Effects of Coinjection of Amlodipine and CWBSD on PE-Induced Contraction. CWBSD more relaxed 


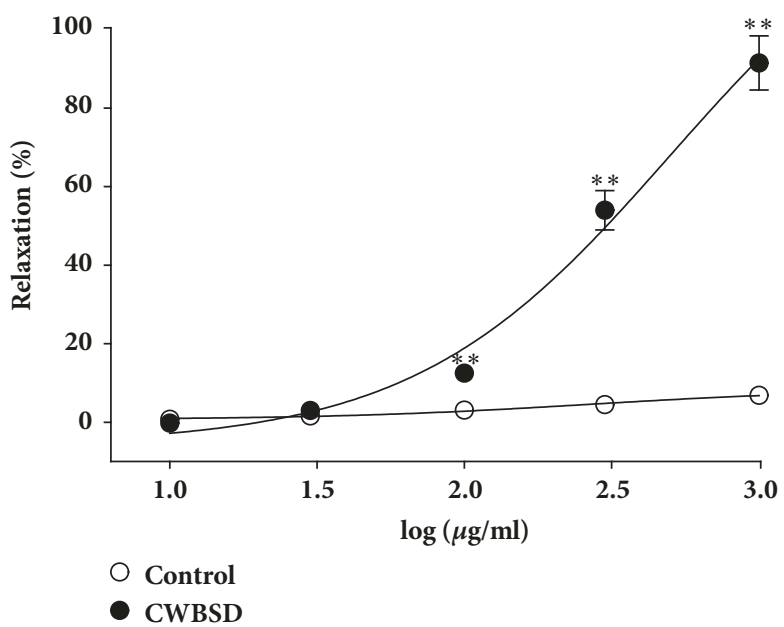

(a)

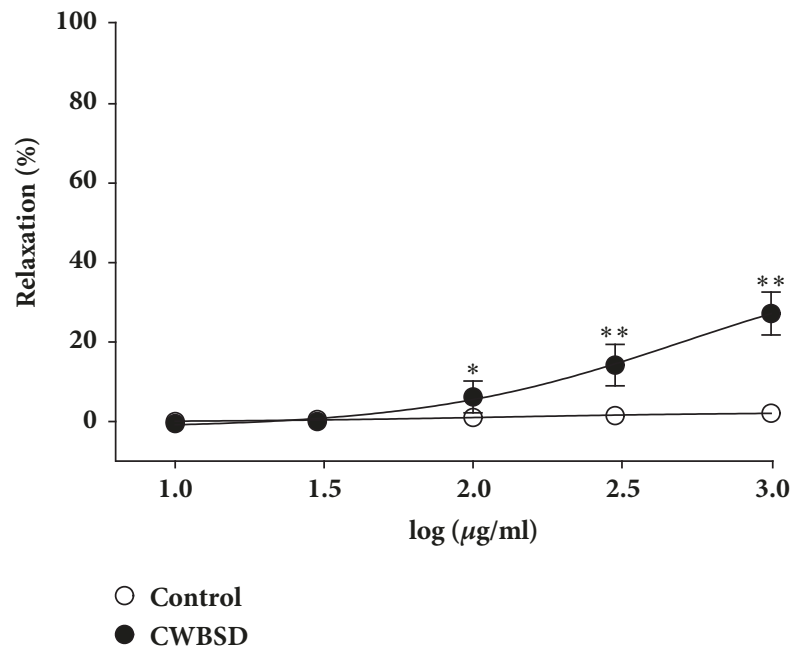

(c)

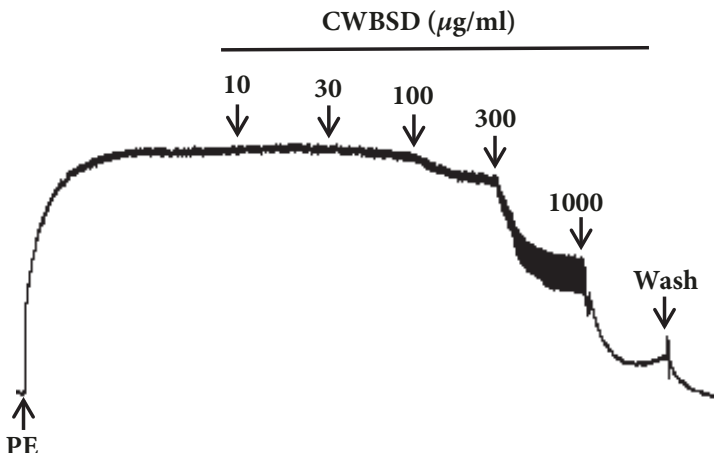

(b)

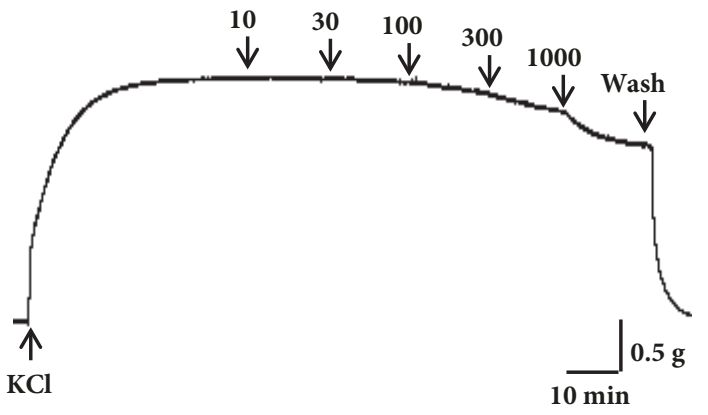

(d)

FIGURE 1: Vasorelaxant effects and representative traces of CWBSD treatment of PE- $(1 \mu \mathrm{M})((\mathrm{a}),(\mathrm{b}))$ or KCl- $(60 \mathrm{mM})((\mathrm{c}),(\mathrm{d}))$ precontracted rat aortic rings. Values are expressed as mean $\pm \operatorname{SEM}(n=5-6) .{ }^{*} p<0.05$ and ${ }^{* *} p<0.01$ vs. control.

isolated rat aortic rings pretreatment with $\mathrm{PE}(1 \mu \mathrm{M})$ which were relaxed by amlodipine $(10 \mu \mathrm{g} / \mathrm{ml})$. The maximal relaxant effect of CWBSD $(1,000 \mu \mathrm{g} / \mathrm{ml})$ was $85.7 \pm 1.8 \%$ compared to control (amlodipine), $48.6 \pm 3.5 \%$ (Figure 3).

3.4. Effects of CWBSD on Blood Pressure in SHRs. CWBSD $(2,476 \mathrm{mg} / \mathrm{kg})$ significantly decreased SBP to $172.7 \pm 11.2$ $(p<0.05)$ and $192.5 \pm 6.8(p<0.05)$ at $1 \mathrm{~h}$ and $4 \mathrm{~h}$ after administration, respectively (Table 2 ).

3.5. Hypotensive Effects of Coadministration of Amlodipine and CWBSD in SHRs. Before oral administration of amlodipine or CWBSD $(0 \mathrm{~h})$, the SBP of the amlodipinetreated group was $218.8 \pm 6.2 \mathrm{mmHg}$ and that of the amlodipine and CWBSD combination treated group was $204.5 \pm$ $12.0 \mathrm{mmHg}$. Four hours after the oral administration of amlodipine or the combination of amlodipine and CWBSD, the SBP of SHRs significantly decreased to $168.6 \pm 1.5 \mathrm{mmHg}$ $(p<0.01)$ or $138.2 \pm 2.8 \mathrm{mmHg}(p<0.01)$ (Table 3$)$, respectively. This effect was stronger in those treated with the combination of amlodipine and CWBSD treatment than those with amlodipine alone $(p<0.01)$ (Table 3$)$.

\section{Discussion}

Recently, various studies have been conducted on the efficacy and safety of common traditional herbal prescriptions, which are widely used in Korea [15-20]. Their interactions with Western medicines also have been researched [21-23].

Hypertension is the most common chronic disease and the worldwide prevalence of hypertension in the adult population has been steadily increasing. There are many hypertensive patients in Korea and most of them take life-long medication for hypertension after the onset of hypertension. THMs for treating hypertension have not yet been developed in Korea. Therefore, patients with hypertension rarely take THMs for the treatment of this disease, but many hypertensive patients take THMs to treat other diseases. For these reasons, patients who take hypotensive drugs often also use THMs simultaneously. However, there are no studies on the 


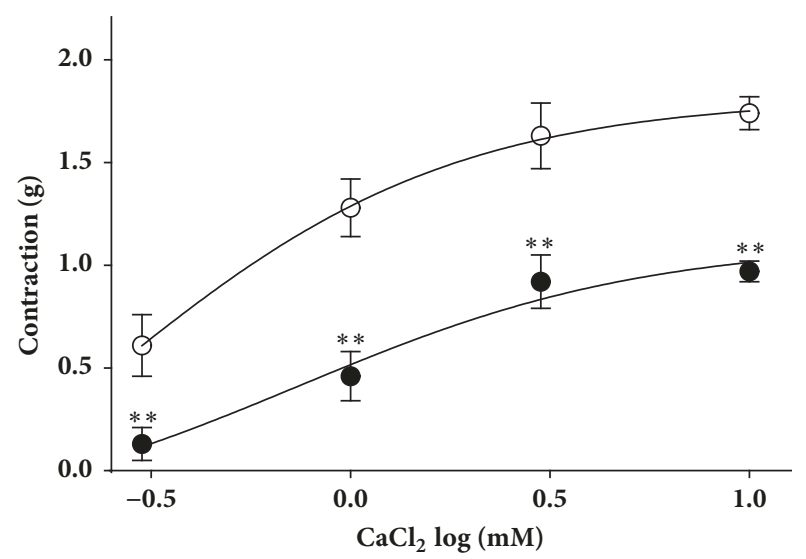

Control

- CWBSD $600 \mu \mathrm{g} / \mathrm{ml}$

(a)

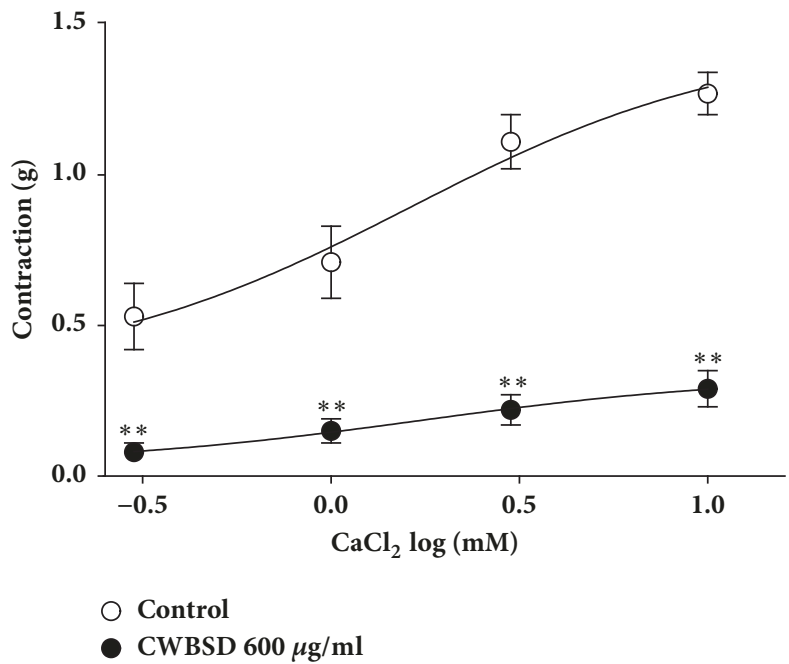

(c)

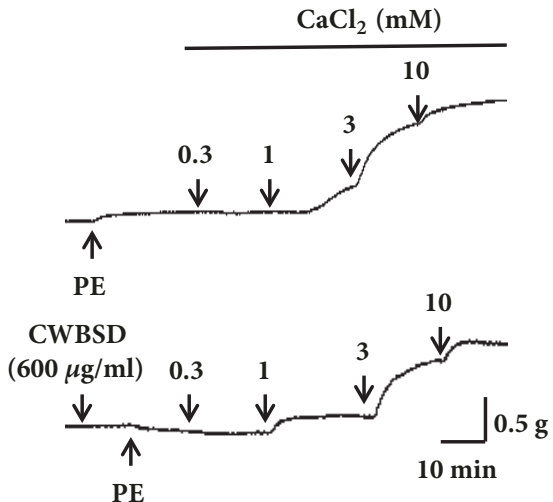

(b)
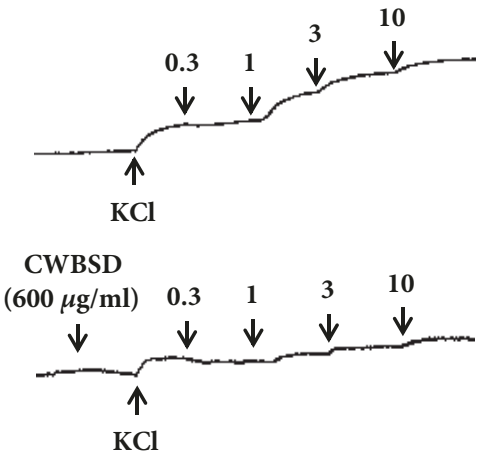

(d)

FIGURE 2: Inhibitory effects of CWBSD $(600 \mu \mathrm{g} / \mathrm{ml})$ on the contraction induced by extracellular $\mathrm{Ca}^{2+}$ in endothelium-denuded rat aortic ring pretreated with PE $(1 \mu \mathrm{M})((\mathrm{a}),(\mathrm{b}))$ or $\mathrm{KCl}(60 \mathrm{mM})((\mathrm{c}),(\mathrm{d}))$ with or without (control) CWBSD. (b) and (d) show representative traces under the indicated conditions. Values are expressed as mean $\pm \operatorname{SEM}(\mathrm{n}=5) .{ }^{* *} P<0.01$ vs. control.

TABLE 2: Effects of CWBSD on blood pressure in SHRs.

\begin{tabular}{|c|c|c|c|c|c|}
\hline & \multicolumn{5}{|c|}{ Systolic blood pressure (mmHg) } \\
\hline & \multicolumn{5}{|c|}{ Time (hour) } \\
\hline CWBSD (mg/kg) & 0 (control) & 0.5 & 1 & 2 & 4 \\
\hline 247.6 & $201.3 \pm 1.7$ & $203.7 \pm 8.0$ & $197.8 \pm 12.1$ & $193.2 \pm 1.9^{*}$ & $207.7 \pm 14.4$ \\
\hline 1,238 & $207.2 \pm 3.8$ & $182.0 \pm 8.2^{*}$ & $218.7 \pm 4.3$ & $219.7 \pm 4.8$ & $198.2 \pm 3.4$ \\
\hline 2,476 & $211.9 \pm 2.3$ & $222.4 \pm 6.4$ & $172.7 \pm 11.2^{*}$ & $194.7 \pm 8.1$ & $192.5 \pm 6.8^{*}$ \\
\hline
\end{tabular}

Values are expressed as mean \pm SEM $(\mathrm{n}=5-8) .{ }^{*} p<0.05$ vs. control.

interactions between, or guidelines for the coadministration of, hypotensive drugs and THMs.

We evaluated the vasorelaxant effects of the traditional herbal prescriptions most commonly used in Korea on the isolated rat aortic rings. Among them, we found that CWBSD has the most pronounced vasorelaxant effect. In this study, we tested the vasorelaxant mechanisms and hypotensive effect of
CWBSD and the vasorelaxant effect and hypotensive effect of combination treatment with CWBSD and amlodipine, which is the most common treatment for hypertension in Korea.

In the present study, CWBSD showed a vasorelaxant effect on isolated rat aortic rings precontracted with $\mathrm{PE}$ or $\mathrm{KCl}$ and a hypotensive effect on SHRs. In addition, it increased the relaxation of rat aortic rings upon the 


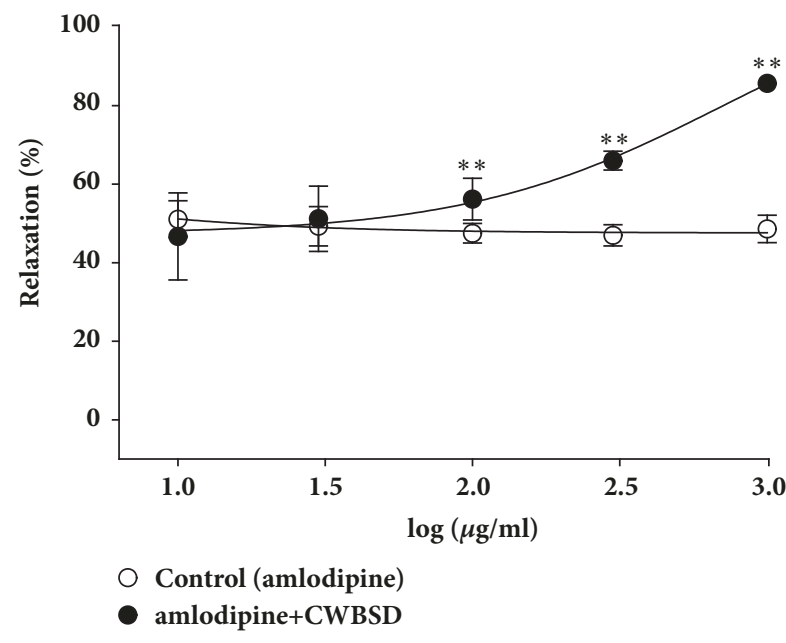

(a)

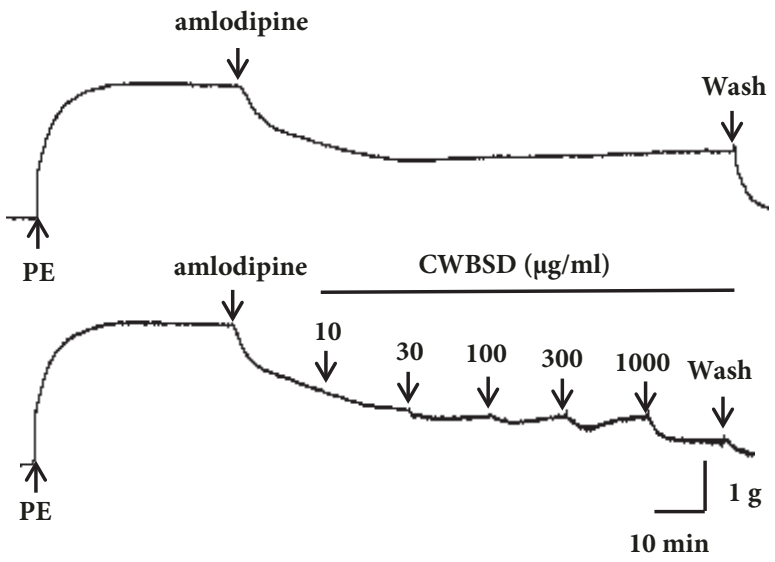

(b)

FIGURE 3: Vasorelaxant effects and representative traces of CWBSD after pretreatment of amlodipine (control) on PE- (1 $\mu \mathrm{M})((\mathrm{a})$ and $(\mathrm{b}))$ precontracted rat aortic rings. Values are expressed as mean $\pm \operatorname{SEM}(\mathrm{n}=5-6) .{ }^{* *} p<0.01$ vs. control.

TABLE 3: Hypotensive effects of coadministration of amlodipine and CWBSD in SHRs.

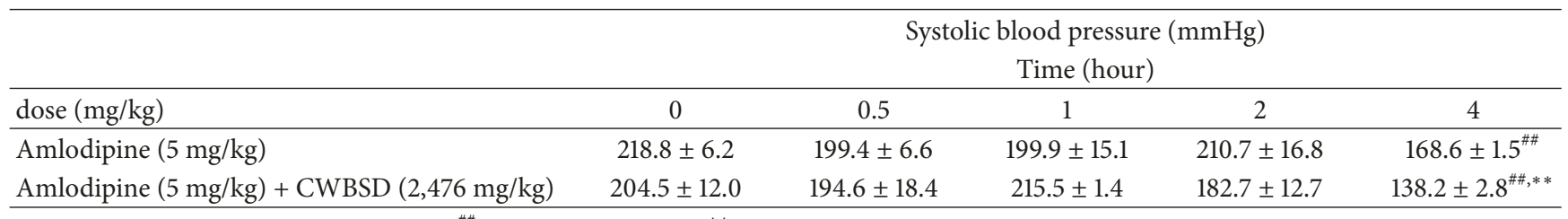

Values are expressed as mean $\pm \operatorname{SEM}(\mathrm{n}=5) .{ }^{\# \#} p<0.01$ vs. 0 h group. ${ }^{* *} p<0.01$ vs. amlodipine group.

addition of amlodipine, and coadministration of CWBSD and amlodipine lowered SBP in SHRs more than amlodipine alone.

One of the most important mechanisms for regulating blood pressure is the calcium channel; therefore calcium channel blockers such as amlodipine are the most commonly used agents for hypertension. Vasodilation in vascular smooth muscle is mainly regulated by two different $\mathrm{Ca}^{2+}$ influx pathways including ROCCs and VDCCs. These channels can be activated by $\mathrm{PE}$ on ROCCs and $\mathrm{KCl}$ on VDCCs [24]. In the present study, CWBSD significantly relaxed isolated rat aortic rings precontracted with $\mathrm{PE}$ or $\mathrm{KCl}$ in a concentration-dependent manner. In addition, CWBSD $(600 \mu \mathrm{g} / \mathrm{ml})$ preincubation for $10 \mathrm{~min}$ significantly inhibited the contraction induced by extracellular $\mathrm{Ca}^{2+}$ in rat aortic rings precontracted by $\mathrm{PE}(1 \mu \mathrm{M})$ or $\mathrm{KCl}(60 \mathrm{mM})$ in $\mathrm{Ca}^{2+}$ free $\mathrm{KH}$ buffer. These results suggest that the vasorelaxant effects of CWBSD are related to inhibition of the influx of extracellular $\mathrm{Ca}^{2+}$ through ROCCs or VDCCs.

CWBSD, one of the most widely used traditional herbal prescriptions in Korea, has been used to treat anxiety disorders such as fright palpitations and fearful throbbing, insomnia, mental fatigue, nocturnal emissions, forgetfulness, dry stool, and stomatitis $[25,26]$. This prescription consists of a mixture of herbal medicines, including Liriopis seu Ophiopogonis Tuber, Schisandrae Fructus, and Salviae Miltiorrhizae Radix, which are helpful in treating hypertension or vascular problems. The ethanol extract of Liriope platyphylla roots improved vascular dysfunction in the aortic rings of SHR by upregulating antioxidant conditions and downregulating potassium ion $\left(\mathrm{K}^{+}\right)$and aldosterone concentrations [27]. Gomisin A from Schisandra chinensis decreased vascular contraction by inhibiting the RhoA/Rho-kinase signaling pathways [28]. Lithospermic acid B isolated from Salviae Miltiorrhizae Radix showed endothelium-dependent vasodilation in the rat aorta [29]. Puerariae Radix and Salviae Miltiorrhizae Radix decoctions induced vasodilation in the porcine coronary artery through blocking L-type calcium channels and opening $\mathrm{K}_{\mathrm{IR}}$ channels [30]. These herbal medicines or active components could be responsible for the vasorelaxant and hypotensive effects of CWBSD.

Amlodipine, widely used for the treatment of hypertension, is the clear market leader in Korea. Many antihypertensive medications, such as Norvasc, Anydipine, and Skad, consist of amlodipine. Korean Statistical Information Service (KOSIS) has reported that Norvasc was one of the Top 10 Imported Drug Products of Korea in 2016, with a value of 33 million dollars [31]. Most patients with hypertension in Korea take hypotensive agents containing amlodipine and many of these patients take several kinds of THMs simultaneously to treat other diseases. In the present study, the combination treatment of amlodipine and CWBSD significantly increased vasorelaxation of $\mathrm{PE}$-precontracted rat aortic rings compared to the amlodipine-only treatment. In addition, 
coadministration of amlodipine and CWBSD also significantly lowered the SBP of SHRs compared to amlodipine alone. These findings suggest that CWBSD does not interfere with the blood-pressure-lowering effect of amlodipine, and it could aid the hypotensive effect of amlodipine through a vasorelaxant effect.

These results suggested that CWBSD could be a useful herbal prescription to treat or prevent hypertension and the hypotensive and vasorelaxant effects of CWBSD were related to attenuation of the influx of extracellular $\mathrm{Ca}^{2+}$ through ROCCs or VDCCs. Hence, CWBSD, which has been used for anxiety disorders, is thought to be promising as a traditional herbal prescription for treating hypertension and we recommend establishing guidelines for the use of herbal medicines for treating hypertension in conjunction with antihypertensive drugs including amlodipine.

\section{Conclusions}

The aim of this study was to investigate the vasorelaxant and hypotensive activities of CWBSD and a combination of CWBSD and amlodipine in isolated rat aortic rings and SHRs. CWBSD showed concentration-dependent vasorelaxant activity in endothelium-intact aortic rings precontracted with $\mathrm{PE}$ or $\mathrm{KCl}$ and lowered the SBP of SHRs. In addition, it increased the relaxation of isolated rat aortic rings induced by amlodipine, and coadministration of amlodipine and CWBSD significantly lowered the SBP of SHRs compared to amlodipine alone. CWBSD relaxed the aortic rings by inhibiting the entry of extracellular $\mathrm{Ca}^{2+}$ via ROCCs and VDCCs. These results could be used as basic data for the development of herbal prescriptions for treating hypertension. In addition, further studies on the mechanisms of action and effective dose of CWBSD, and the combination of CWBSD and amlodipine, may provide evidence for the safe administration of CWBSD in patients with hypertension.

\section{Data Availability}

The data used to support the findings of this study are available from the corresponding author upon request.

\section{Conflicts of Interest}

The authors have declared that there are no conflicts of interest.

\section{Authors' Contributions}

Bumjung Kim participated in the data analysis and drafted this paper. Bumjung Kim and Cheolmin Jo carried out the animal experiment. Ho-Young Choi and Kyungjin Lee were supervisors for this research and participated in both the study design and critical revision of the paper and all agreed to accept equal responsibility for the accuracy of the content of the paper.

\section{Acknowledgments}

This research was supported by the grant "Evaluation of Herb-Drug Interactions (K16252)" from the Korea Institute of Oriental Medicine (KIOM).

\section{References}

[1] Lung National Heart, The seventh report of the joint national committee on prevention, detection, evaluation, and treatment of high blood pressure, National Heart, Lung, and Blood Institute, 2004.

[2] H. Lee and J. B. Park, "The Korean Society of Hypertension Guidelines for the Management of Hypertension in 2013: Its Essentials and Key Points," Pulse, vol. 3, no. 1, pp. 21-28, 2015.

[3] N. R. Kim and H. C. Kim, "Prevalence and trends of isolated systolic hypertension among Korean adults: The Korea national health and nutrition examination survey, 1998-2012," Korean Circulation Journal, vol. 45, no. 6, pp. 492-499, 2015.

[4] K.-H. Leem and H.-K. Park, "Traditional Korean medicine: now and the future," Neurological Research, vol. 29, supplement 1, pp. 3-4, 2007.

[5] I. A. Oreagba, K. A. Oshikoya, and M. Amachree, "Herbal medicine use among urban residents in Lagos, Nigeria," BMC Complementary and Alternative Medicine, vol. 11, article 117, 2011.

[6] C.-S. Seo and H.-K. Shin, "Development and validation of a high-performance liquid chromatographic method for the simultaneous quantification of marker constituents in cheonwangbosimdan," Natural Product Communications (NPC), vol. 9, no. 12, pp. 1751-1754, 2014.

[7] C.-S. Seo, O. S. Kim, and H.-K. Shin, "Quantitative determination and antioxidant effects of Cheonwangbosimdan," Korean Journal of Pharmacognosy, vol. 45, no. 4, pp. 300-314, 2014.

[8] J. H. Park, C. W. Bae, and H. S. Jun, "Antidepressant effect of Chunwangboshimdan and its influence on monoamines," The Korean Journal of Oriental Medical Prescription, vol. 12, no. 2, pp. 77-93, 2004.

[9] S. H. Kim, J. W. Kim, and C. H. Kang, "The effects of Chenwangbosim-dan and herbs on mouse neuroblastoma $2 \mathrm{a}$ cells damaged by hypoxia-reoxygenation," Journal of Oriental Neuropsychiatry, vol. 17, no. 2, pp. 15-36, 2006.

[10] T. Teaford, R. J. Shaw, A. Reiss, and L. Lotspeich, "Pseudologia fantastica associated with pervasive developmental disorder," Psychiatry, vol. 65, no. 2, pp. 165-171, 2002.

[11] I. C. Jung, S. R. Lee, and Y. C. Park, "The effect of saam acupuncture simjeongkyeok treatment for major sympom of hwa-byung," Journal of Oriental Neuropsychiatry, vol. 19, no. 1, pp. 1-18, 2008.

[12] I. C. Jung, "Effects of Chenwhangbosim-dan and Sungsimjihwang-tang on protecting microglia and inhibiting acetylcholinesterase and oxidants," Journal of physiology pathology in Korean Medicine, vol. 22, no. 1, pp. 120-125, 2008.

[13] P. Liu, X.-R. He, W.-B. Zhou, R.-R. Shen, and F. Feng, "Research for dependablity of administration of platycodi radix in Tianwang Buxinwan decoction with change of brain inhibitive neurotransmitte in rats by microdialysis," Zhongguo Zhongyao Zazhi, vol. 33, no. 23, pp. 2830-2833, 2008.

[14] N. J. Kim, Y. Y. Kong, and S. W. Chang, "Studies on the efficacy of combined preparation of crude drugs (XXXVII). The effects of Chunwangboshimdan on the central nervous system and 
cardio-vascular system," Korean Journal of Pharmacognosy, vol. 19, no. 3, pp. 208-215, 1988.

[15] Soo-Jin Jeong, Sae-Rom Yoo, Ohn-Soon Kim, Chang-Seob Seo, and Hyeun-Kyoo Shin, "Antioxidant and Antiadipogenic Activities of Galkeun-Tang, a Traditional Korean Herbal Formula," Evidence-Based Complementary and Alternative Medicine, vol. 2014, Article ID 763494, 9 pages, 2014.

[16] M.-Y. Lee, I.-S. Shin, W.-Y. Jeon et al., "Protective effect of Bojungikki-tang, a traditional herbal formula, against alcoholinduced gastric injury in rats," Journal of Ethnopharmacology, vol. 142, no. 2, pp. 346-353, 2012.

[17] S.-J. Jeong, H.-S. Lim, C.-S. Seo et al., "Anti-inflammatory actions of herbal formula Gyejibokryeong-hwan regulated by inhibiting chemokine production and STAT1 activation in HaCaT cells," Biological \& Pharmaceutical Bulletin, vol. 38, no. 3, pp. 425-434, 2015.

[18] M.-Y. Lee, I.-S. Shin, C.-S. Seo, J.-H. Kim, S.-R. Han, and H.-K. Shin, "Subchronic oral toxicity studies of the traditional herbal formula Bangpungtongseong-san in Crl: CD (SD) rats," Journal of Ethnopharmacology, vol. 144, no. 3, pp. 720-725, 2012.

[19] S.-J. Jeong, C.-S. Seo, J.-I. Huh, and H.-K. Shin, "Subacute oral toxicity of Yukmijiwhang-Tang in crl:CD sprague-dawley rats and its cytotoxicity," Evidence-Based Complementary and Alternative Medicine, vol. 2014, Article ID 362573, 11 pages, 2014.

[20] M.-Y. Lee, C.-S. Seo, Y.-B. Kim, and H.-K. Shin, "Safety assessment of Guibi-tang: Subchronic toxicity study in Crl: CD SD rats," Regulatory Toxicology and Pharmacology, vol. 73, no. 2, pp. 485-493, 2015.

[21] S. Y. Fong, Qiong Gao, and Zhong Zuo, "Interaction of carbamazepine with herbs, dietary supplements, and food: a systematic review," Evidence-Based Complementary and Alternative Medicine, vol. 2013, Article ID 898261, 15 pages, 2013.

[22] Q. Zhao, J. Jiang, and P. Hu, "Effects of four traditional Chinese medicines on the pharmacokinetics of simvastatin," Xenobiotica, vol. 45, no. 9, pp. 803-810, 2015.

[23] Y. Lu, Z. Gong, Y. Xie et al., "Herb-Drug Interaction: Effects of Relinqing ${ }^{\circledR}$ Granule on the Pharmacokinetics of Ciprofloxacin, Sulfamethoxazole, and Trimethoprim in Rats," Evidence-Based Complementary and Alternative Medicine, vol. 2016, Article ID 6194206, 6 pages, 2016.

[24] S.-Z. Hoe, C.-N. Lee, S.-L. Mok, M. Y. Kamaruddin, and S.K. Lam, "Gynura procumbens Merr. decreases blood pressure in rats by vasodilatation via inhibition of calcium channels," Clinics, vol. 66, no. 1, pp. 143-150, 2011.

[25] J. Heo, Donguibogam, Bubin, Republic of Korea, 1st edition, 2011.

[26] Herbal formulation Professors of Korean Medicine, Herbal Formulation, Younglimsa, Republic of Korea, 4th edition, 2012.

[27] Y. Lee, E. Koh, J. Kim et al., "Beneficial effects of ethanol extracts of Red ," Laboratory Animal Research, vol. 31, no. 1, p. 13, 2015.

[28] Y. M. Seok, Y. W. Choi, G.-D. Kim, H. Y. Kim, Y. Takuwa, and I. K. Kim, "Effects of gomisin A on vascular contraction in rat aortic rings," Naunyn-Schmiedeberg's Archives of Pharmacology, vol. 383, no. 1, pp. 45-56, 2011.

[29] K. Kamata, T. Iizuka, M. Nagai, and Y. Kasuya, "Endotheliumdependent vasodilator effects of the extract from Salviae Miltiorrhizae radix. A study on the identification of lithospermic acid B in the extracts," General Pharmacology: The Vascular System, vol. 24, no. 4, pp. 977-981, 1993.

[30] F. Hu, C. M. Koon, J. Y. W. Chan, K. M. Lau, Y. W. Kwan, and K. P. Fung, "Involvements of calcium channel and potassium channel in Danshen and Gegen decoction induced vasodilation in porcine coronary LAD artery," Phytomedicine, vol. 19, no. 12, pp. 1051-1058, 2012.

[31] "Korean Statistical Information Service (KOSIS), Top $10 \mathrm{im}$ ported drug products," 2018, http://Kosis.kr/statHtml/statHtml .do?orgId=145\&amp;tblId=DT_145009_016\&amp;conn_path= I2. 


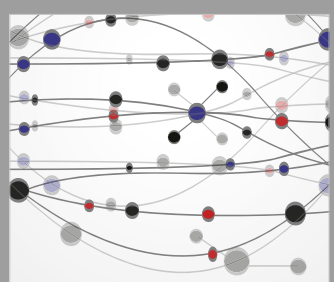

The Scientific World Journal
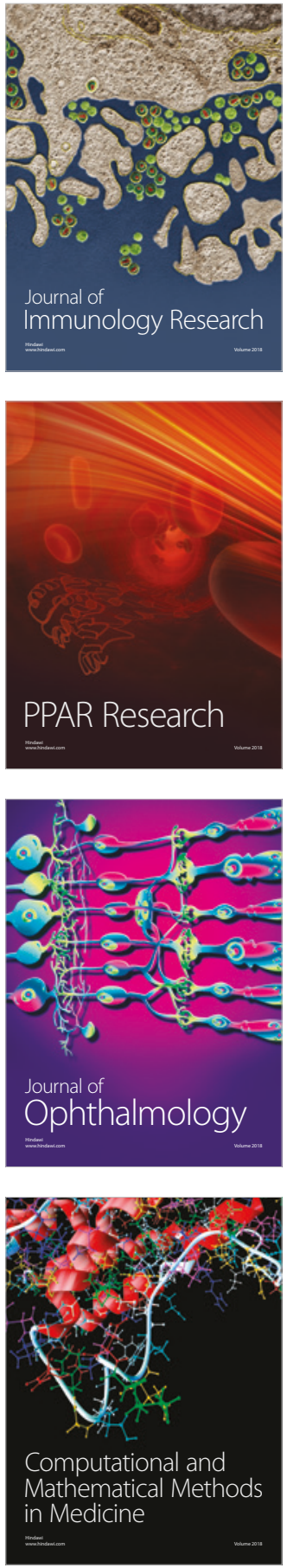

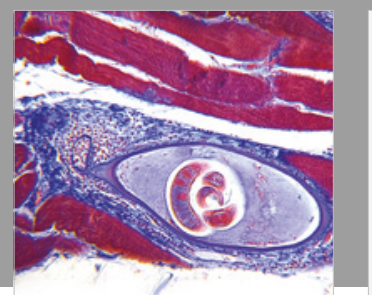

Gastroenterology Research and Practice

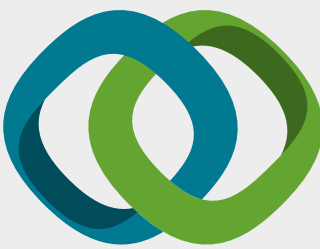

\section{Hindawi}

Submit your manuscripts at

www.hindawi.com
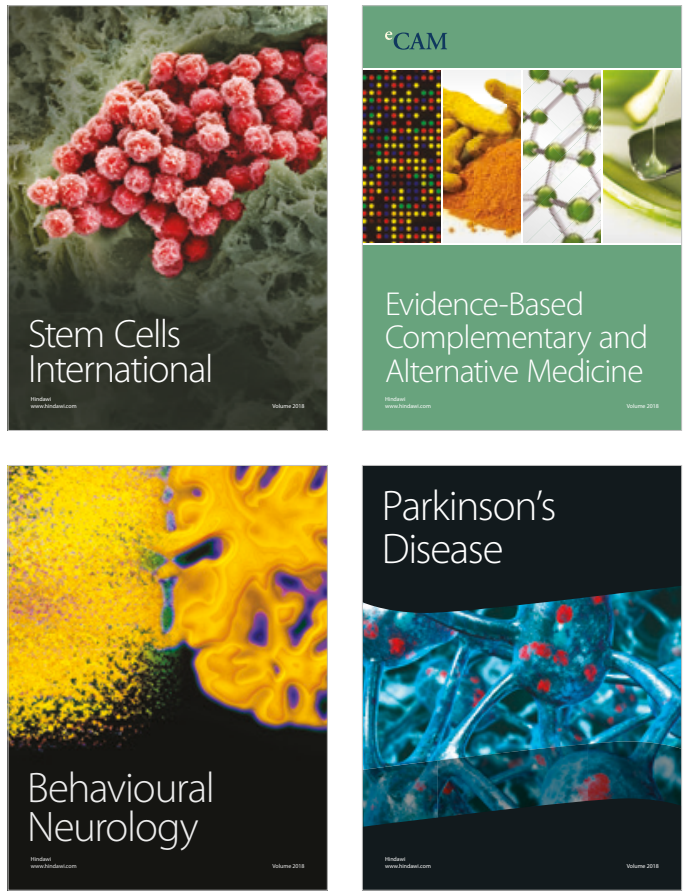

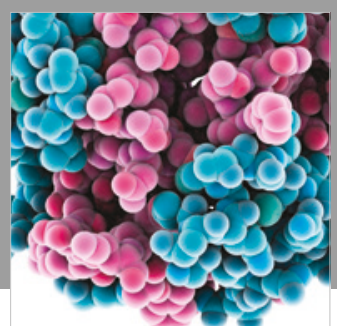

ournal of

Diabetes Research

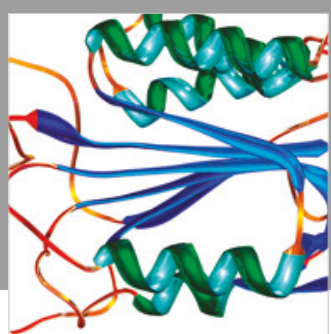

Disease Markers
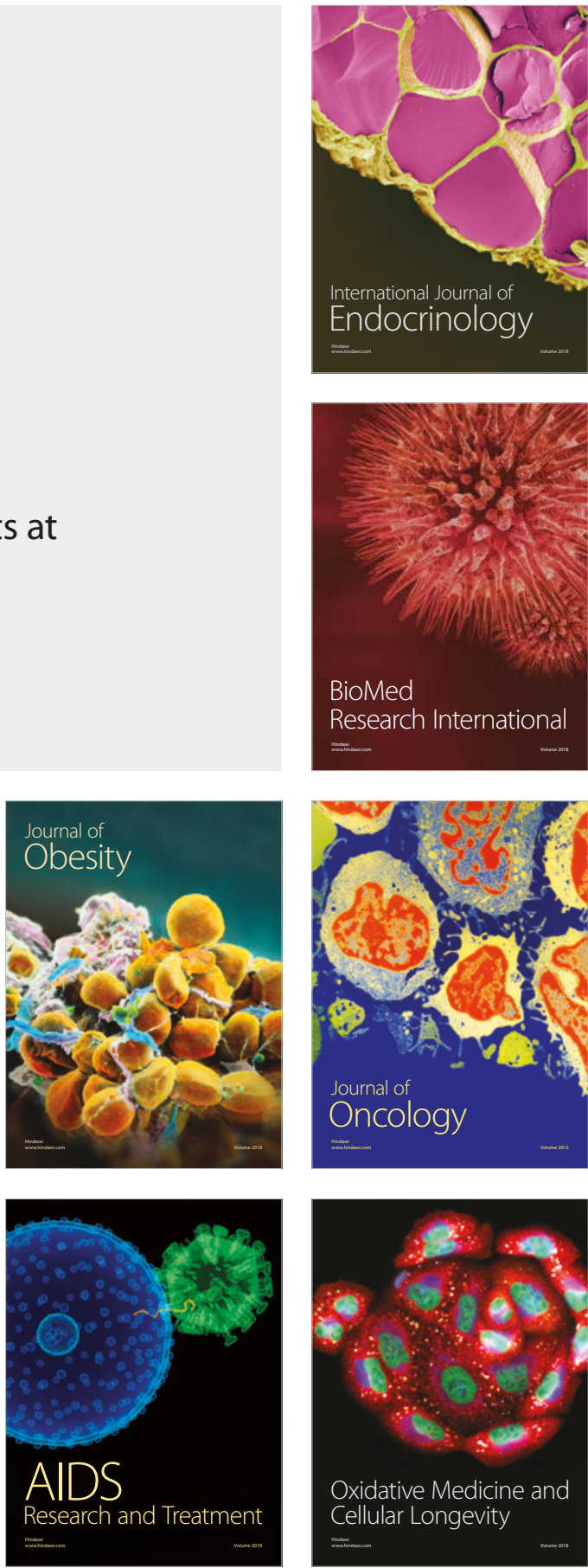